\title{
The Ultrastructural Architecture of the Walls of Some Hyphal Fungi
}

\author{
By D. HUNSLEY* AND J. H. BURNETT \\ The Department of Botany, The University, Glasgow, W.2
}

(Accepted for publication 28 April 1970)

\begin{abstract}
SUMMARY
The appearance of the walls of apical and sub-apical regions of hyphae of predominantly 5 day cultures of Neurospora crassa, Schizophyllum commune and Phytophthora parasitica as seen with the electron microscope, employing shadowed or sectioned material, is illustrated and described in detail. The appearance of untreated or control material in buffer is compared with that exposed to various single and sequential treatments with enzymes, including laminarinase, Pronase, cellulase and chitinase, as well as various chemical treatments.

From these observations is inferred the co-axial distribution of polymers such as $\beta \mathrm{I}, 3-, \beta \mathrm{I}, 6-$ glucans, glycoproteins, proteins, chitin and cellulose in the walls of each species. The distributions have both similarities and differences between the species. The significance of all these features for the growth, mechanical rigidity and integrity of a hypha is briefly discussed.
\end{abstract}

\section{INTRODUCTION}

The growth of fungal hyphae is not well understood. One reason for this is that the molecular architecture of hyphal walls has not received sufficient attention. Chemical studies are beginning to reveal the complexity of hyphal wall components (e.g. review, Bartnicki-Garcia, I968), while studies with enzymes have indicated that they are arranged in definite layers, e.g. in Neurospora crassa (Potgieter \& Alexander, 1965). Only a little information is available concerning wall structure as revealed by electron microscopy (e.g. review, Aronson, 1965) and this is either based mostly on residual shadowed material after drastic chemical treatments, or from thin sections which alone are not very informative.

In this paper we describe the consequences of treating hyphae with enzymes, singly or successively, and then examining both shadow-cast and sectioned material with an electron microscope. The three species studied were selected because they differ in the chemistry of their cell walls, which was relatively well known from studies by other investigators. This new approach provides information on a comparative basis, concerning the distribution and arrangement of certain kinds of polymers within hyphal walls.

\section{METHODS}

Organisms. The organisms used were as follows: an ascomycete, Neurospora crassa, wild type, Emerson A from the Neurospora stock cultures; Schizophyllum commune, a basidiomycete, was isolated from damp plywood in Newcastle upon

* Present address: Department of Agricultural Science, University of Oxford, Parks Road, Oxford, OX I 3 PF. 
Tyne; and Phytophthora parasitica Dastur, strain T89, an oomycete, was kindly supplied by Dr S. Bartnicki-Garcia, University of California, who had analysed its walls.

Culture media and conditions. Neurospora crassa. Ammonium tartrate $5 \cdot 0$ g.; $\mathrm{NH}_{4}$ $\mathrm{NO}_{3}$, I.० g.; $\mathrm{MgSO}_{4} \cdot 7 \mathrm{H}_{2} \mathrm{O}, 0.5 \mathrm{~g}$.; $\mathrm{NaCl}$, O.I g.; $\mathrm{KH}_{2} \mathrm{PO}_{4}$, I.O g.; $\mathrm{CaCl}_{2} \cdot 7 \mathrm{H}_{2} \mathrm{O}$, $0.1 \mathrm{~g}$; biotin, $5 \times 1 \mathrm{IO}^{-6} \mathrm{~g}$.; B, $0.0 \mathrm{I} \mathrm{mg.;} \mathrm{Cu,} \mathrm{0.1} \mathrm{mg.;} \mathrm{Fe,} 0.2 \mathrm{mg}$.; $\mathrm{Mn}, 0.02 \mathrm{mg}$.; Mo, 0.02 mg.; $\mathrm{Zn}, 2.0 \mathrm{mg}$; sucrose, $15 \mathrm{~g}$.; distilled water, I l.; $(\mathrm{pH}=5.6)$ (Beadle \& Tatum, 1945). Schizophyllum commune. L-Asparagine, I.5 g.; $\mathrm{KH}_{2} \mathrm{PO}_{4}, 0.46 \mathrm{~g}$.; $\mathrm{K}_{2} \mathrm{H} \mathrm{PO}_{4}$, I. 0 g.; $\mathrm{MgSO}_{4} \cdot 7 \mathrm{H}_{2} \mathrm{O}, 0.5 \mathrm{~g}$.; dextrose, 20 g.; distilled water, I 1. Phytophthora parasitica. $\mathrm{KH}_{2} \mathrm{PO}_{4}, 3 \mathrm{~g}$.; L-asparagine, $2 \mathrm{~g}$.; $\mathrm{MgSO}_{4} .7 \mathrm{H}_{2} \mathrm{O}, 0.5 \mathrm{~g}$.; Ammonium molybdate, $0.3 \mathrm{mg}$.; $\mathrm{CaCl}_{2} \cdot 7 \mathrm{H}_{2} \mathrm{O}, 3.4 \mathrm{mg}$.; $\mathrm{FeSO}_{4} \cdot 7 \mathrm{H}_{2} \mathrm{O}, \mathrm{I} \mathrm{mg}$. with citric acid, I. $4 \mathrm{mg}$.; $\mathrm{MnSO}_{4} . \mathrm{H}_{2} \mathrm{O}, 0.3 \mathrm{mg}$; thiamine- $\mathrm{HCl}$, I mg.; dextrose, $20 \mathrm{~g}$.; distilled water, to $\mathrm{I} 1$.

Media were autoclaved at I 5 p.s.i. for $15 \mathrm{~min}$. Minerals and sugars were autoclaved separately. Fungi were grown in $30 \mathrm{ml}$. volumes of medium in $150 \mathrm{ml}$. Erhlenmeyer flasks on an orbital shaker at $150 \mathrm{rev} . / \mathrm{min}$. for 5 days at $25^{\circ}$, or, in a few cases, for 24 h. only.

Mycelium for use in the enzymic dissection experiments was centrifuged down from the medium in sterile centrifuge tubes and washed once with sterile distilled water.

Enzymes. The enzymes used were: cellulase (E.C. 3.2. I .4), Pronase (a commercial mixture of proteolytic enzymes) and chitinase (E.C. 3.2.I. I4), all from Koch-Light Laboratories Ltd, Colnbrook, Buckinghamshire, and a bacterial laminarinase (E.C. 3.2. I .6) supplied by Glaxo Ltd and employed previously by Manners and his colleagues (Manners \& Patterson, I966; Fleming, Manners \& Masson, 1967).

Intact mycelium was incubated with each enzyme for $48 \mathrm{~h}$. at $37^{\circ}$ in $\mathrm{Na}_{2} \mathrm{HPO}_{4}-$ acetic acid buffer on a reciprocal shaker. Cellulase and the laminarinase were used at $\mathrm{pH} 5.0$, chitinase at $\mathrm{pH} 5.5$ and Pronase at $\mathrm{pH} 7.5$. For each experiment $\mathrm{I} 8 \mathrm{ml}$. of buffer was used to which was added $2 \mathrm{ml}$. of a suspension of the enzyme concerned containing $0.5 \mathrm{mg}$. enzyme $/ \mathrm{ml}$. More concentrated dispersions of enzymes were not used since preliminary experiments showed that final concentrations of $\mathrm{I} \mathrm{mg} . / \mathrm{ml}$. tended to obscure the hyphal material when it was examined in the electron microscope.

The long incubation time was used to give the Pronase time to react since it was being used at $18^{\circ}$ below its optimum temperature. This avoided incubation of live mycelia in buffer at $55^{\circ}$ which might have produced cellular artefacts. A $48 \mathrm{~h}$. incubation time was, therefore, adopted as a standard.

Chitinase, the laminarinase and Pronase were used on Neurospora and Schizophyllum; cellulase, Pronase and the laminarinase on Phytophthora.

If only one enzyme was effective initially, the mycelium of each species was treated for $48 \mathrm{~h}$. to remove what was presumably the outer layer of wall material, centrifuged, washed in sterile distilled water and then treated separately for a further $48 \mathrm{~h}$. with each of the remaining two enzymes in an appropriate buffer. If only one of these enzymes was effective, a final experiment was set up where mycelium was treated with the first two enzymes in the appropriate order for the usual time and then for $48 \mathrm{~h}$. with the remaining enzyme.

For every treatment controls were set up where mycelium was incubated with appropriate buffers and boiled enzymes to ensure that incubation in buffer alone did not remove wall material. 
Tests of purity of enzymes. It was essential to ascertain that each enzyme did not grossly degrade substrates of any of the other enzymes used. Accordingly, each enzyme was incubated with the substrate of the other enzymes for $24 \mathrm{~h}$. at $37^{\circ}$ and the mixture tested for degradation products. Chitin was obtained from Koch-Light Laboratories. It was purified by dissolving in conc. $\mathrm{HCl}$ at $3^{\circ}$, filtering through glass wool, and pouring the filtrate into vigorously stirred $50 \%$ aqueous ethanol. The precipitate was washed with distilled water several times (Skujins, Potgieter \& Alexander, 1965) and freeze-dried. Laminarin was provided by the Institute of Seaweed Research, Musselburgh, Midlothian, and was further purified by preparing a Io $\%$ solution in hot distilled water, filtering and recrystallizing. After three further washings in cold distilled water the residue was freeze-dried and stored for use. Cellulose (chromatographic grade) and bovine albumin were obtained from KochLight Laboratories and used without any further purification.

Chitin was tested for production of $\mathrm{N}$-acetyl glucosamine using Erhlich's reagent (Tracey, 1955). Laminarin and cellulose were tested for production of reducing sugars using Nelson's reagent (Nelson, 1944) and albumin for production of amino acids using ninhydrin (Cocking \& Yemm, 1954). When testing for amino acids, residual intact proteins were removed by precipitating with $10 \%$ trichloroacetic acid followed by filtration.

Controls were run in which each substrate was incubated in the appropriate buffer only, for $48 \mathrm{~h}$., and each enzyme was also incubated for $48 \mathrm{~h}$. in buffer alone. Because reducing sugars were found in the commercial preparation of cellulase, these were removed by passing a suspension of the enzyme, in buffer, down a Sephadex G 25 column. No evidence was provided by these tests that any of the enzymes employed grossly degraded any substrate other than that for which they were supposedly specific. The cellulase was found to have slight laminarinase activity. The laminarin controls produced a considerable amount of reducing sugar after $48 \mathrm{~h}$. but only a little after $\mathrm{I} h$.; this was probably due in part to spontaneous hydrolysis of laminarin. However, treatment with Pronase and chitinase for $\mathrm{I}$ h. showed no increased production of reducing sugar compared with the control, whereas treatment with laminarinase and, to a slight extent, with cellulase, did.

\section{Electron microscopical techniques}

(i) Shadow casting. After treatment experimental material was washed once in distilled water, blended in an MSE microblender and dried down on to grids coated with formvar and carbon. The grids were then shadowed with $\mathrm{Au} / \mathrm{Pd}(60 / 40)$ at $\tan ^{-1} \frac{1}{3}$ at a pressure of $10^{-5}$ torr and examined in an AEI EM6B electron microscope.

(ii) Sectioning. Experimental material was fixed in $2 \%$ aqueous $\mathrm{KMnO}_{4}$ at room temperature for $75 \mathrm{~min}$. For purposes of comparison, untreated material was fixed in $5 \%$ phosphate-buffered glutaraldehyde at $\mathrm{pH} 7.4$ for $4.5 \mathrm{~h}$. (Sabatini, Bensch \& Barnett, 1963), washed overnight in buffer, postfixed in $1 \%$ phosphate-buffered $\mathrm{OsO}_{4}$, dehydrated by a graded ethanol series and embedded in Araldite (Luft, I96I). Permanganate-fixed sections were stained for $4 \mathrm{~min}$. with lead citrate (Reynolds, 1963). Glutaraldehyde $/ \mathrm{OsO}_{4}$-fixed material was stained for $2 \mathrm{~h}$. in $2 \%$ uranyl acetate in $50 \%$ ethanol during dehydration and, after sectioning, with basic lead citrate as above.

(iii) The preparation of microfibrillar residues from mycelial material. Residual 
microfibrillar material was prepared by a drastic chemical treatment already described (Hunsley \& Burnett, I968). Briefly, this treatment involves an initial extraction with boiling water, then hot absolute ethanol followed by $\mathrm{I} 2$ to $24 \mathrm{~h}$. treatment with $5 \%(\mathrm{w} / \mathrm{v}) \mathrm{KOH}$ at room temperature. After a brief treatment with hot $5 \%(\mathrm{v} / \mathrm{v})$ acetic acid, the material is oxidized for $\mathrm{I} 2$ to $24 \mathrm{~h}$. with $2 \%(\mathrm{w} / \mathrm{v}) \mathrm{KMnO}_{4}$ at room temperature. It is then washed in oxalic acid, boiled for $30 \mathrm{~min}$. in $0.5 \mathrm{NHCl}$ and, after several washes in distilled water, dried down on grids and shadowed.

(iv) Additional treatment. To confirm one of the results, intact Neurospora mycelium was treated for $5 \mathrm{~min}$. in an MSE IOo W ultrasonic disintegrator, washed, dried down and shadowed as already described. Precautions were taken to ensure that mycelial material did not overheat during this treatment.

\section{RESULTS}

The consequences of the enzymic treatments of 5 day mycelial cultures as they appeared when examined by electron microscopy are set out separately for each species.

\section{Neurospora crassa}

Shadow-cast preparations of the surface of hyphae of control material present a somewhat granular, amorphous appearance both at the apex and sub-apically (Pl. I, fig. I, 2). The three-layered, mature wall is of the order of $140 \mathrm{~nm}$. thick with a central, electron-dense zone (PI. 7, fig. 36, 37). The surface appearance did not differ from that given by a 5 day hypha which was dried down and shadow-cast without incubation in buffer. Neither chitinase (Pl. I, fig. 3, 4; Pl. 7, fig. 38) nor Pronase (P1. I, fig. 5, 6; Pl. 7, fig. 39) treatments materially affected these appearances or the thickness of mature walls. The distinctness of the wall layers in permanganate-fixed material was, however, reduced somewhat.

In contrast, treatment with laminarinase removed the outer, amorphous layer to reveal, eventually, a network of coarse strands whose interstices were filled with amorphous material in older wall areas, giving a cratered appearance; but at apices, where the reticulum was less well developed, the strands were not so clear (PI. 2, fig. 7,9$)$. Occasionally the reticulum appeared to be of predominantly longitudinally arranged strands, especially in the outer part of this region (Pl. 2, fig. 8). In section, the strands often appeared separate from the underlying wall region (Pl. 7, fig. 40).

Laminarinase/Pronase treatment resulted in a better definition of the reticulum strands, presumably by removing the amorphous material from interstices (Pl. 2, fig. I I). In material treated only with laminarinase, the reticulum appears in surface view to be coincident with the inner wall regions (Pl. 2, fig. 7, 9), but, with subsequent Pronase treatment, material removed at the level of the reticulum and from beneath it gave rise to a clear region outside the inner regions (P1. 2, fig. II). This can be seen to the left of the arrow on Pl. 2, fig. I I. Not only is this separation more evident in sections ( $\mathrm{Pl}$. 7, fig. 4I) but, in some instances, the reticulum can be seen to have slipped off the end of the inner regions (Pl. 2, fig. I2). Moreover, evidence that this remarkable structure is not an artefact of enzyme treatment is provided by the fact that it can be revealed after a brief $(5 \mathrm{~min}$.) ultrasonic treatment of intact hyphae (P1. 2, fig. IO). 
The radial thickness of the strands can be calculated from the length of the shadows in preparations such as those illustrated in P1. 2, fig. I2, and the tangential thickness can be measured directly from shadow-cast preparations or from tangential sections such as Pl. 3, fig. I3. The values obtained in these ways range from to to $45 \mathrm{~nm}$. (tangential) to io to $35 \mathrm{~nm}$. (radial). The distance between the reticulum and the underlying layers can be calculated from the clear region of overlap visible in PI. 2, fig. II. (To measure this distance, only preparations with an equal overlap on both sides of the central hyphal region were used.)

In addition, the effects of the laminarinase/Pronase treatment can include the dissolution of the reticulum (Pl. 3, fig. I4) but this is more frequent after an additional subsequent laminarinase treatment. The removal of the reticulum, through its sliding off, or by enzymic degradation, reveals an amorphous region of low electron density (Pl. 3, fig. I5). Continued laminarinase/Pronase treatment also reveals microfibrils both at the apex and distally (P1. 3, fig. I6, I7) whose dimensions lie within those of the residual microfibrils of chitin revealed in Neurospora walls by drastic chemical treatments (Hunsley \& Burnett, I968). A laminarinase/Pronase/chitinase sequence resulted in the degradation of these microfibrils (Pl. 3, fig. I 8; Pl. 7, fig. 43). Although the shadowcast appearance of a wall after laminarinase/chitinase treatment was indistinguishable from that after a laminarinase treatment, the wall appeared thinner and less organized after the former process in sectioned material (Pl. 7, cf. fig. 40, 42; see also Potgieter \& Alexander, 1965).

\section{Schizophyllum commune}

The appearance of shadow-cast preparations of the surface of hyphae of control material of this species (PI. 4, fig. I9, 20) was similar to, but less coarsely granular than, that of Neurospora. Treatment with laminarinase, Pronase or chitinase resulted in no appreciable change. The apparently four-layered mature wall was unaffected by such treatments, and was of the order of $210 \mathrm{~nm}$. thick (Pl. 7, fig. 44, 45), save for reduced clarity of the wall's layers. The lack of effect of these enzymes is not surprising since Wessels (I965) showed that Schizophyllum walls contain S-glucan, probably an $\alpha$ I,3 glucose polymer (Bacon, Jones, Farmer \& Webley, 1968; J. G. H. Wessels, personal communication), which could be removed by treatment with $\mathrm{KOH}$ at room temperature for $17.5 \mathrm{~h}$. The material removed could be reprecipitated from $\mathrm{KOH}$ by bringing the $\mathrm{pH}$ to 4 with glacial acetic acid.

$\mathrm{KOH}$ treatment was applied to a mycelium which was then washed five times with sterile, distilled water. Shadow-cast preparations of such material presented an irregularly roughened appearance at the hyphal surface of sub-apical regions (P1. 4, fig. 22) and the walls were now only $I 20 \mathrm{~nm}$. thick (Pl. 7, fig. 46). Apices were less rough (Pl. 4, fig. 2I).

It was presumed that the outermost S-glucan had been removed. Hyphae so treated were now susceptible to attack by laminarinase alone. This revealed a finely granular, amorphous layer both at apices and further back, beneath which microfibrils could be discerned in outline only (Pl. 4, fig. 23, 24). Residual material after $\mathrm{KOH} /$ laminarinase treatment was only $85 \mathrm{~nm}$. thick in section (Pl. 7, fig. 47).

$\mathrm{KOH} /$ Pronase and $\mathrm{KOH} /$ chitinase treatments did not appear to be more effective than $\mathrm{KOH}$ alone, but the sequence $\mathrm{KOH} /$ laminarinase/Pronase unmasked the microfibrils which appeared to be disposed at random (Pl. 5, fig. 25, 26). These fell within 
the limits which had been found for chitin from this fungus after drastic chemical treatment (Hunsley \& Burnett, I968). The microfibrillar layer was about $60 \mathrm{~nm}$. thick in a mature wall as seen in section (P1. 7, fig. 48). A further treatment with chitinase of material in which the microfibrillar layer had been exposed resulted in its virtual dissolution (Pl. 5, fig. 27; Pl. 7, fig. 49).

\section{Phytophthora parasitica}

The surface of the hyphae of this species is the same whether seen in shadow-cast preparations of control material, or in material treated with cellulase or Pronase: it is finely granular and amorphous (Pl. 5, fig. 28, 29). The two-layered wall of a mature hypha in section is of the order of $20 \mathrm{~nm}$. thick and even permanganate fixation hardly affects its appearance (Pl. 7, fig. 50, 5I).

After treatment with laminarinase the thickness was usually reduced to about $125 \mathrm{~nm}$. (P1. 7, fig. 52) but could be as little as $100 \mathrm{~nm}$. The surface appearance revealed the outlines of microfibrils (Pl. 6, fig. 30, 3I) of dimensions within the limits of those of cellulose found after drastic chemical treatment (Hunsley \& Burnett, I968). In sub-apical regions of the walls, these microfibrils appeared to be arranged predominantly transversely to the long axis of the hypha in the outer part of the region although at random further in (cf. Pl. 6, fig. 3I, 33). If laminarinase/Pronase treatments were employed, the microfibrils appeared much sharper in surface view. This 'cleaning-up' was more noticeable in sub-apical areas than at apices (P1. 6, fig. 32, 33). The cellulosic nature of the microfibrils was confirmed in laminarinase/ cellulase-treated walls where there was almost total digestion, leaving a hyphal 'ghost' in surface view, presumably a proteinaceous shell (P1. 6, fig. 34, 35).

In section, laminarinase and laminarinase/cellulase-treated walls differed a little in thickness, the latter often being somewhat thicker (about $150 \mathrm{~nm}$. compared with 100 to $\mathrm{I} 25 \mathrm{~nm}$.), and in appearance. Laminarinase/cellulase-treated walls were less electron-dense and uniformly granular compared with the more electron-dense and amorphous laminarin-treated walls. In contrast, laminarinase/Pronase-treated walls were more electron-dense than laminarinase/cellulase-treated walls, with an irregularly granular appearance and unevenly distributed, clear areas, but not so electron-dense as walls treated with laminarinase alone. Laminarinase/Pronase walls too were usually notably thicker (about $160 \mathrm{~nm}$.) than walls treated only with laminarinase.

No recognizable residues were left after either laminarinase/Pronase/cellulase or laminarinase/cellulase/Pronase-treatments and, in section, only the plasmalemma was detectable (Pl. 7, fig. 55).

\section{Hyphal apices}

All three species were exposed to the drastic chemical treatments already described by Hunsley \& Burnett (I968) and, in every case, an intact microfibrillar mesh was found to enclose the apices (Pl. 8, fig. 56 to 58). These residual microfibrils were of chitin in Neurospora and Schizophyllum and of cellulose in Phytophthora as determined by enzymic digestion. Residual microfibrils did not appear to be orientated predominantly in any one direction at the apices. 


\section{Young hyphae of Neurospora}

Twenty-four h. cultures of Neurospora were examined by drying down hyphae on grids and shadow-casting them. Their appearance differed from 5 day hyphae. A reticular appearance was readily visible without further treatment but did not extend up to the apex (PI. 8, fig. 59, 60). Indeed, the appearance of such hyphae suggested that the reticulum developed progressively from behind the apex and rearwards. The appearance of the region behind the apex in a $24 \mathrm{~h}$. culture was extremely reminiscent of that of the reticulum layer revealed after laminarinase or laminarinase/Pronase treatment of 5 day hyphae (cf. Pl. 8, fig. 60 with Pl. 2, fig. 9, II, I2).

A

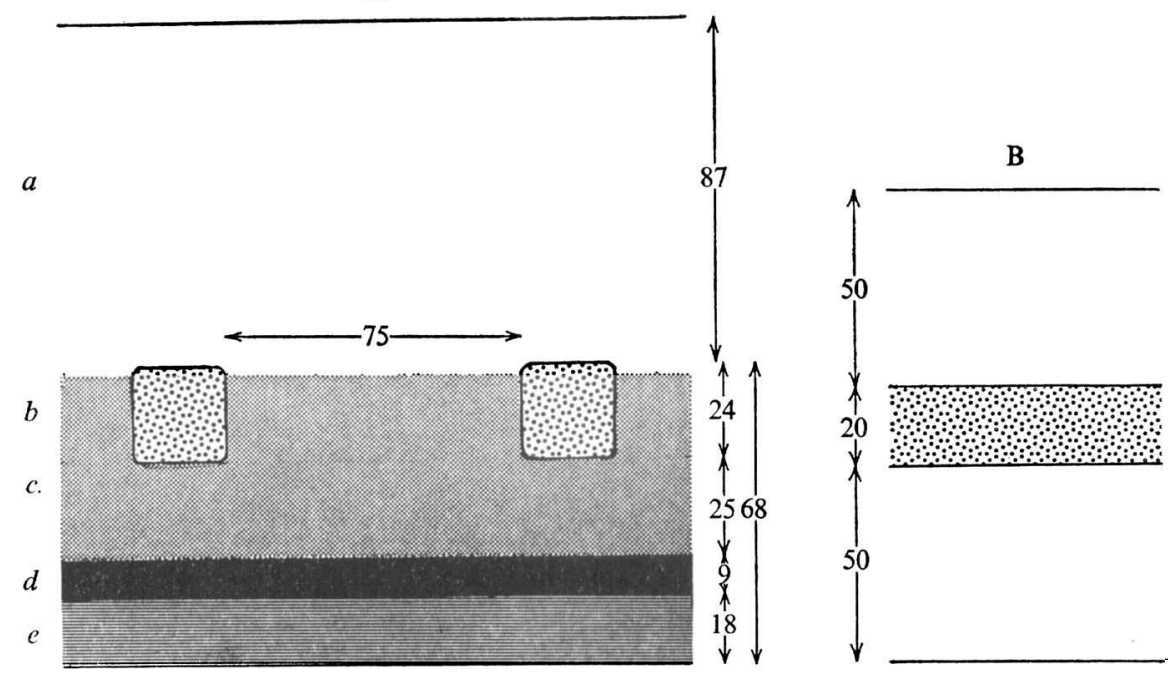

Fig. I. Neurospora crassa.

(A) Reconstruction of section through the wall of a hypha from a 5 day culture, based on enzyme-dissection experiments. The numbers represent the mean thickness of the layers in $\mathrm{nm}$. (a) Outermost layer of amorphous glucan containing $\beta_{\mathrm{I}, 3}$ and $\beta_{\mathrm{I}}, 6$ linkages. (b) Sections through coarse strands of (?) glycoprotein reticulum. (c) Easily removable protein in which reticulum is embedded; there is an increasing concentration of protein from the outer part of this region inwards. (d) A discrete layer of protein. (e) Innermost layer of chitin microfibrils possibly intermixed with protein. (B) Layers visible in a section of an untreated wall from a 5 day culture fixed in glutaraldehyde/ $\mathrm{OsO}_{4}$; the middle layer is more electron-opaque than the other two. Based on Pl. 7, fig. 36.

\section{Interpretation and reconstruction}

\section{DISCUSSION}

It is possible using shadow-cast preparations to infer the co-axial distribution of certain wall polymers in hyphal fungi from the consequences of applying certain sequences and combinations of enzymes which degrade them from outside inwards. Estimates of the thickness of each co-axial region can be obtained from measurements of walls in section after being subjected to identical enzymic treatments.

Figure I A to $3 \mathrm{~A}$ are diagrammatic reconstructions of walls behind the apex for each species in 5 day cultures. Figure 1 B to 3 B, based on Pl. 7 , fig. $36,44,50$, are provided 
for comparison: they represent the layers which could be distinguished by their electron opacity or appearance in ultrathin sections of untreated walls of the same species in 5 day cultures. Reconstructions of walls in the apical regions of 5 day cultures, or for $24 \mathrm{~h}$. cultures are not given here since we do not yet possess sufficiently detailed information about such regions and hyphae.

It can be seen in Phytophthora and Schizophyllum and to some extent in Neurospora that the reconstructions of the wall layers are commensurate with the layers

A

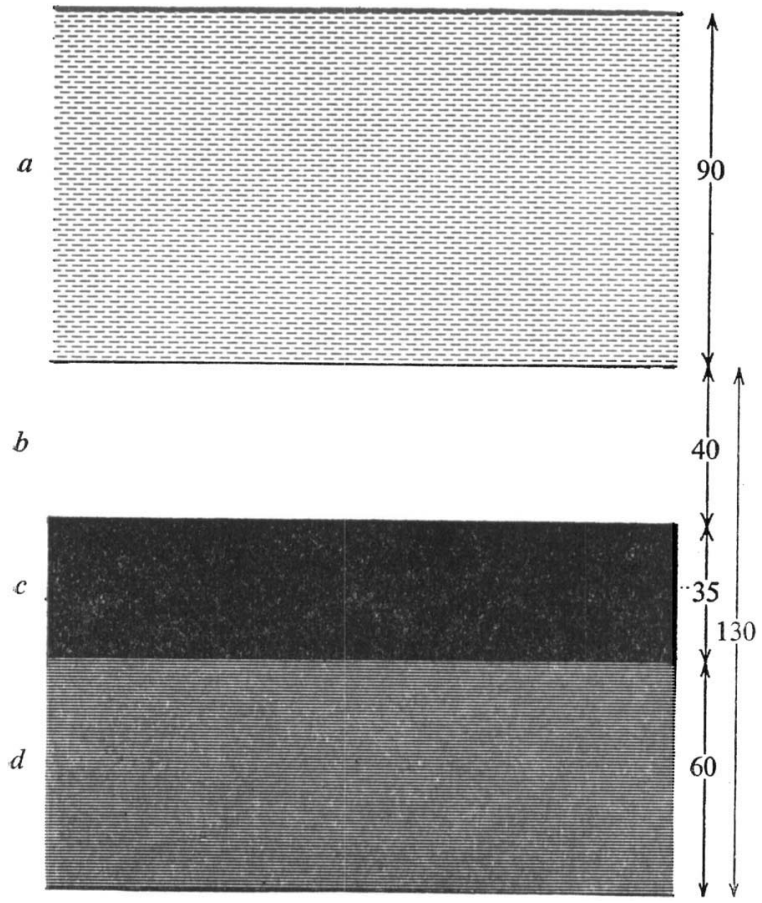

B

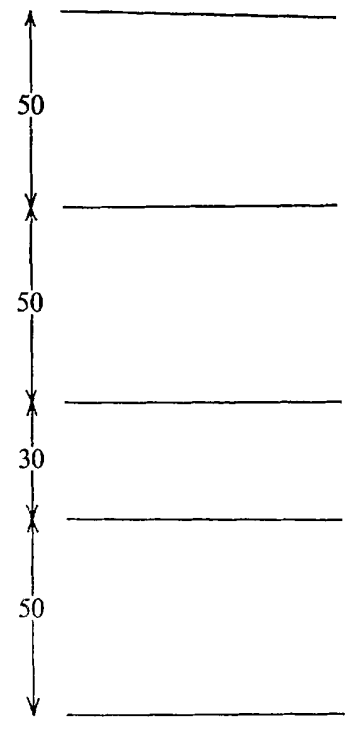

Fig. 2. Schizophyllum commune.

(A) Reconstruction of section through the wall of a hypha from a 5 day culture, based on KOH- and enzyme-dissection experiments. The numbers represent the mean thickness of the layers in $\mathrm{nm}$. (a) Outermost, amorphous glucan layer, possibly containing $\alpha \mathrm{I}, 3$ linkages and soluble in cold $\mathrm{KOH}$; the S-glucan of Wessels (I965). (b) Amorphous glucan containing $\beta_{\mathbf{I}, 3}$ and $\beta \mathbf{I}, 6$ linkages; the R-glucan of Wessels. (c) A discrete layer of protein. $(d)$ Innermost layer of chitin microfibrils possibly intermixed with protein. (B) Layers visible in a section of an untreated wall from a 5 day culture, fixed in glutaraldehyde/OsO ${ }_{4}$. There is no marked difference in the electron opacity of the four layers. Based on P1. 7, fig. 44 .

recognizable in sections of untreated walls. It is now possible to suggest a chemical and structural basis for some of these co-axial regions but some ambiguities still remain. These will be considered together with data by other techniques and workers for each species.

Neurospora crassa. Both Potgieter \& Alexander (1965) and Mahadevan \& Tatum (I965, I967) observed that chitin and glucan were the predominant wall materials and that the former was surrounded, or protected, by the latter. This is consistent 
with our demonstration that chitin forms the innermost co-axial region. It seems to us that the reticulum region can best be equated to the glycoprotein complex (glucanpeptide-galactosamine) reported by Mahadevan \& Tatum (1967) and isolated by them as a distinct alkali-soluble fraction which gave rise to glucose, glucuronic acid, galactosamine and amino acids on hydrolysis. They described the complex as forming thick fibrils in the outer part of the wall. In our study, the reticulum was susceptible to degradation both by Pronase and laminarinase and was most effectively dispersed by treatment with both enzymes. Our technique would detect neither glucuronic acid

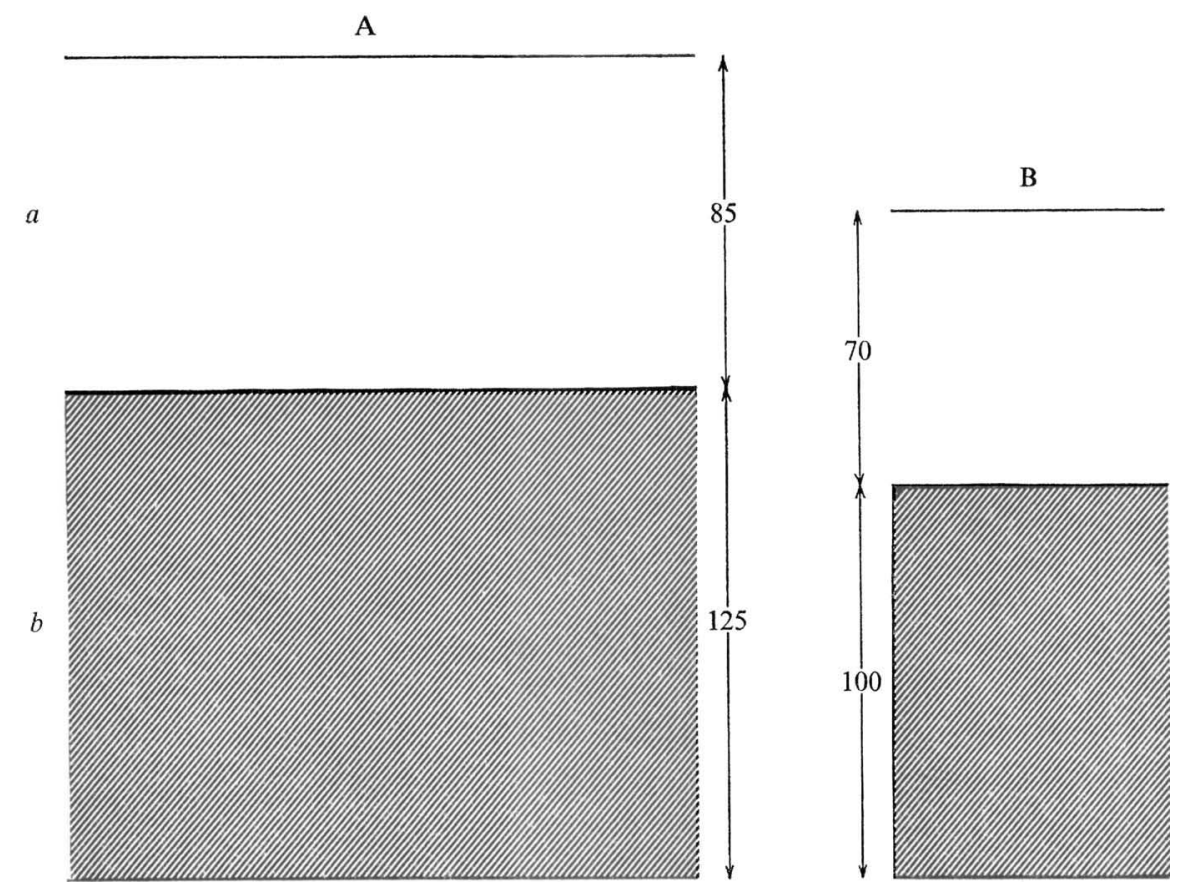

Fig. 3. Phytophthora parasitica.

(A) Reconstruction of section through the wall of a hypha from a 5 day culture, based on enzyme-dissection experiments. The numbers represent the mean thickness of the layers in $\mathrm{nm}$. (a) Outermost layer of amorphous glucan containing $\beta \mathrm{I}, 3$ and $\beta \mathrm{I}, 6$ linkages. (b) Innermost layer of cellulose microfibrils and protein. (B) Wall layers visible in a section of an untreated wall from a 5 day culture, fixed in glutaraldehyde $/ \mathrm{OsO}_{4}$. The inner layer is more electron-opaque. Based on Pl. 7, fig. 50.

nor galactosamine but it is not inconceivable that mechanical dissolution-the process we observed-could be brought about by the destruction of peptide and glycosidic bonds alone. The extent to which protein permeates this and other regions and is chemically attached to other wall components is not wholly resolved by our technique. We suggest that protein occurs in the interstices of the reticulum and that the wall becomes progressively protein-rich from the outside of this region inwards until it forms a discrete layer on the surface of the chitinous region. Indeed, protein may well permeate this innermost co-axial region since the microfibrils, once revealed, become more distinct with pronase treatment. This widespread distribution of protein is compatible with claims that protein accounts for $14 \%$ of wall material as estimated 
from total $\mathrm{N}$ values. The nature of the glucan is not known with certainty and the claim that it may include $\beta \mathbf{I}, 3$ and $\beta \mathbf{I}, 6$ linkages (Mahadevan \& Tatum, I965; Potgieter \& Alexander, 1965) is not incompatible with our use of a glucanase which was effective both on laminarin (predominantly $\beta \mathrm{I}, 3$ linkages and some $\beta_{\mathrm{I}, 6}$ linkages; cf. Percival, 1962) and R-glucan in Schizophyllum, which is said to have both types of linkages in it (Wessels, I965).

Schizophyllum commune. The presence of S-glucan, probably containing $\alpha \mathrm{I}, 3$ linkages, as the outermost co-axial region differentiates this fungus from Neurospora, as does the absence of a reticulum region. The possible significance of this is discussed later. Once again, the distribution of protein has not been fully ascertained but here too there was a discrete protein layer overlying the chitin, and protein probably extends amongst the microfibrils.

Phytophthora parasitica. Although the innermost co-axial region was predominantly cellulose or, at least, $\beta \mathrm{I}, 4$ glucan, laminarinase-soluble glucan still formed the outermost layer of the wall. This is consistent with Zevenhuizen \& Bartnicki-Garcia's (1969) observations on the residual glucan of the wall of Phytophthora cinnamoni after removal of cellulose. This was said to contain $\beta_{\mathrm{I}, 3}$ and $\beta_{\mathrm{I}, 6}$ linkages and may be structurally similar to insoluble cell wall (yeast) glucan of Saccharomyces cerevisiae (Peat, Whelan \& Edwards, I958). It is not clear what significance can be attributed to the apparent absence of a distinct protein layer overlying the cellulose but it is clear that the microfibrils were embedded in protein, possibly throughout the region. It is possible that protein-cellulose linkages exist. It will be recalled that if either the cellulose or protein was removed from the cellulose/protein region it appeared thicker in section than when intact (p. 208). This could be accounted for if both polymers were normally linked, but if unlinked became liable to radial stretching. The occurrence of hydroxyproline in the walls of this species (BartnickiGarcia, I966) also supports this view if Lamport's (1965) claim that it provides an important glycosidic link between polysaccharides and proteins is true.

\section{The mechanical integrity of mature walls}

The mechanical integrity of mature hyphal walls, i.e. those away from the apex in 5 day cultures, does not seem to reside in any one major wall component. Our evidence for this is that (i) hyphal disintegration only occurred following enzymic sequences attacking all the principal components in all three species, and (ii) even when walls of Phytophthora parasitica were reduced to cellulose/protein, removal of either alone was insufficient to cause disintegration. Additional evidence derived from growing fungi in wall-degrading enzymes has been cited by Robertson and his co-workers (Robertson \& Rizvi, 1965; Robertson, 1968). Manocha \& Colvin (1967) suggest that wall protein may be responsible for the retention of wall morphology in Neurospora crassa after enzymic attack. Nevertheless, there is a good deal of evidence that the apex is more susceptible to rupture than are mature walls. So mechanical integrity could be related to differences in wall construction between these regions. A number of such regional differences have been observed in our studies. These are listed below.

I. In Neurospora crassa, the reticulum was neither so well developed nor did it appear to have so much interstitial protein at the apex as sub-apically. Moreover, in 
intact, untreated hyphae of $24 \mathrm{~h}$. cultures the reticulum could actually be seen, albeit indistinctly, in sub-apical regions but was apparently absent at the apex. This, taken with observations on 5 day cultures, suggests that in $N$. crassa both reticulum development and the thickening of the outermost glucan region are features of maturing hyphae.

2. Treatment of Schizophyllum commune with $\mathrm{KOH}$ to remove S-glucan roughened the outer surface less at the apex than sub-apically. This could be because there was less S-glucan at the apex than elsewhere.

3. In Phytophthora parasitica, laminarinase/Pronase-treated walls showed more striking cleaning-up of cellulose microfibrils in sub-apical regions than at the apex. This suggests that there is less protein at the apex than further back.

4. The dimensions of residual microfibrillar elements after drastic chemical removal of matrix materials in all three species were less in apical than in sub-apical regions (Hunsley \& Burnett, I968).

We suggest, therefore, that the innermost wall areas of protein + chitin (or protein + cellulose in Phytophthora) with perhaps a little outer glucan form a mechanically intact but non-rigid wall at the apex. This is not at variance with Robertson's (1959) demonstration of the apparently great plasticity of the hyphal apex. Moreover, the development of outer regions which proceeds progressively further back from the apex imposes an increasing degree of rigidification as required by Robertson's (I959) observations. This additional strengthening may be achieved in at least three ways: in Neurospora crassa, by reticulum development plus outer glucan; in Schizophyllum commune, by the outermost S-glucan (for the inner R-glucan is readily dissolved by the fungus (Wessels, 1965, 1966)); and in Phytophthora parasitica by outer glucan. Why, in chitin-containing walls, two methods of additional strengthening have been adopted is unclear. Two suggestions may be made. $N$. crassa is an extremely rapidly growing fungus compared with $S$. commune, in favourable conditions at least, and the coarsely stranded reticulum may provide a more effective, perhaps more elastic, strengthening device than the mere addition of peripheral amorphous material. Alternatively, the reticulum region in $N$. crassa could serve some function entirely different from wall strengthening, and one which is either not possessed or not well developed in $S$. commune. It is easy to explain the absence of a reticulum at the apex of an hypha of a $24 \mathrm{~h}$. culture and its presence, poorly developed, in an enzymically treated 5 day culture. In the conditions we employed for culture, the nutrients were virtually exhausted after 5 days, and we suggest that in such circumstances extension growth at the tip had become reduced but reticulum-layer differentiation had continued. Thus reticulum development had, so to speak, overtaken the reduced extension growth of the apex. This implies a balance between extension growth at the tip and reticulum development in a normally growing hypha; presumably this balance is regulated internally. It provides a structural basis, in Neurospora, for a balance between the hypothetical processes of extension growth and rigidification postulated by Robertson (1959).

Apical growth. Our observations provide no direct information concerning the mechanism of apical extension growth in fungi, but they do establish certain minimal requirements for the process. First, in the three species studied here as well as in Phycomyces blakesleeanus (Houwink in Roelofsen, 1959), Gonapodya sp., Allomyces macrogynus (Aronson \& Preston, I960a, b), Polyporus myllitae (Scurfield, I967), 
Fusarium sp., Polystictus versicolor and Rhizina undulata (D. Hunsley, unpublished) there is clear evidence that when exposed to enzymic, or drastic chemical treatments, hyphal apices still possess microfibrillar components lacking any well-defined angle of orientation. This is important since it has been claimed that hyphal tips either lack microfibrillar components or that they are artefacts of chemical treatment (Marchant, I966) or that they do not extend to the extreme tip where there is an apical pore free of microfibrils (Strunk 1963, 1968). Since we observed microfibrils after both enzymic and chemical treatments, we reject Marchant's view. We also concur with Scurfield's (1967) suggestion that Strunk had been misled by observing a septum with a central pore where a hypha had broken and mistaking it for an hyphal apex. Secondly, our results reported here indicate that the apical region also includes matrix materials, notably protein which may surround and overlie the microfibrils and itself be covered by a thin layer of $\beta_{\mathrm{I}, 3}, \beta_{\mathrm{I}}, 6$ glucan or perhaps, in Schizophyllum, $\alpha \mathrm{I}, 3$ glucan. So that to account for simple hyphal growth the following requirements must be met:

(i) Chitin (or cellulose) microfibrils must be formed at the apex together with protein and $\beta \mathrm{I}, 3, \beta_{\mathrm{I}, 6}$ glucan (or $\alpha_{\mathrm{I}, 3}$ glucan).

(ii) The apex must be so organized that a more or less co-axial sequence of polymers can be derived, glucan outside, protein and chitin (or cellulose) within.

(iii) Sub-apically, the degree of aggregation of the ultimate microfibrils must somehow increase to account for the observed increase in the diameter of the microfibrils (Hunsley \& Burnett, 1968).

(iv) In the same sub-apical region new polymers must arise and be orientated so that they come to lie between the outermost and innermost co-axial regions, e.g. the (?) glycoprotein reticulum of Neurospora, R-glucan of Schizophyllum.

How these requirements can be related to vesicular or other systems within the plasmalemma which supposedly bring wall materials, or their precursors to the apical region is not yet clear. It is encouraging to note that the young, actively growing apical walls of some fungi, such as Neurospora crassa, are simpler in their molecular architecture than are older walls, or less actively growing tips. But it is equally clear such apparent simplicity is still, in fact, complex and requires further study.

This work was supported by the Science Research Council by grant B/SR/5096 (J.H.B.) and a studentship (D.H.), and we are also grateful to Glaxo Limited and the Institute of Seaweed Research, Musselburgh, Scotland, for gifts of bacterial laminarinase and laminarin, respectively.

\section{REFERENCES}

Aronson, J. M. (1965). The cell wall. In The Fungi, vol. I, chap. 3, pp. 49-76. Edited by G. C. Ainsworth \& A. S. Sussmann. New York: Academic Press.

Aronson, J. M. \& Preston, R. D. (I960a). An electron microscopic and X-ray analysis of the walls of selected lower phycomycetes. Proceedings of the Royal Society, B 152, 346-352.

Aronson, J. M. \& Preston, R. D. (I $960 b$ ). The microfibrillar structure of the cell walls of the fungus Allomyces. Journal of Biophysical and Biochemical Cytology 8, 247-256.

Bacon, J. S. D., Jones, D., Farmer, V. C. \& Webley, D. M. (I968). The occurrence of $\alpha(\mathrm{I}-3)$ glucan in Cryptococcus, Schizosaccharomyces and Polyporus species, and its hydrolysis by a Streptomyces culture filtrate lysing cell walls of Cryptococcus. Biochimica et Biophysica Acta 158, 313-315. 
BartNICKI-GarCiA, S. (1968). Cell wall chemistry, morphogenesis and taxonomy of fungi. Annual Review of Microbiology 22, 87-108.

BARTNICKI-GARCIA, S. (1966). Chemistry of hyphal walls of Phytophthora. Journal of General Microbiology 42, 57-69.

BEAdLE, L. C. \& TATUM, E. L. (1945). Neurospora II. Methods of producing and detecting mutations concerned with nutritional requirements. American Journal of Botany 32, 678-685.

Cocking, E. C. \& YeMM, E. W. (I954). Estimation of amino acids by ninhydrin. Biochemical Journal 58 , xii.

Fleming, M., Manners, D. J. \& Masson, A. J. (1967). The enzymic degradation of laminarin. Biochemical Journal 104, 32-33.

Houwink, A. L. (1959). Plate 6, Fig. 210, in The Plant Cell Wall. P. A. Roelofsen. Berlin: Borntraeger.

Hunsley, D. \& Burnett, J. H. (1968). Dimensions of microfibrillar elements in fungal walls. Nature, London 218, 462-463.

LAMPORT, D. T. A. (I965). The protein component of primary cell walls. Advances in Botanical Research 2, $15 \mathrm{I}-213$.

LuFT, J. H. (I96I). Improvements in epoxy resin embedding methods. Journal of Biophysical and Biochemical Cytology 9, 409-4I4.

MahadeVAn, P. R. \& TATUM, E. L. (I965). Relationship of the major constituents of the Neurospora crassa cell wall to wild-type and colonial morphology. Journal of Bacteriology 90, 1073-1081.

MahadeVAN, P. R. \& TATUM, E. L. (1967). Localization of structural polymers in the cell wall of Neurospora crassa. Journal of Cell Biology 35, 295-302.

Manners, D. J. \& Patterson, J. C. (1966). A re-examination of the molecular structure of yeast glucan. Biochemical Journal 98, 19C-20 C.

ManOCHA, M. S. \& Colvin, J. R. (1967). Structure and composition of the cell wall of Neurospora crassa. Journal of Bacteriology 94, 202-2 I 2.

Marchant, R. (I966). Wall structure and spore germination in Fusarium culmorum. Annals of Botany 30, 82 I-830.

Nelson, N. (1944). A photometric adaptation of the Somogyi method for the determination of glucose. Journal of Biological Chemistry 153, 375-380.

Peat, S., Whelan, W. J. \& Edwards, T. E. (1958). Polysaccharides of baker's yeast. Part II: Yeast glucan. Journal of the Chemical Society 3862-3868.

Percival, E. (I962). Structural Carbohydrate Chemistry, pp. 264-268. London: Garnett Miller.

Potgieter, H. J. \& AleXander, M. (1965). Polysaccharide components of Neurospora crassa hyphal walls. Canadian Journal of Microbiology Ir, I22-I25.

REYNoLds, E. S. (1963). The use of lead citrate at high pH as an electron-opaque stain in electron microscopy. Journal of Biophysical and Biochemical Cytology 17, 208-212.

Rizvi, S. R. H. \& Robertson, N. F. (1965). Apical disintegration of hyphae of Neurospora crassa as a response to L-sorbose. Transactions of the British Mycological Society 48, 469-477.

RoBertson, N. F. (1959). Experimental control of hyphal branching and branch form in hyphomycetous fungi. Journal of the Linnean Society 56, 207-21 I.

Robertson, N. F. (1968). The growth process in fungi. Annual Review of Microbiology 6, II3-I36.

SABatini, D. D., Bensch, K. \& BaRnetr, R. J. (1963). The preservation of cellular ultrastructure and enzymatic activity by aldehyde fixation. Journal of Cell Biology $\mathbf{1 7}, 19-58$.

SCURFIELD, G. (1967). Apical pore in fungal hyphae. Nature, London 214, 740-741.

Skujins, J. J., Potgieter, H. J. \& Alexander, M. (1965). Dissolution of fungal cell walls by a streptomycete chitinase and $\beta$ (I-3)-glucanase. Archives of Biochemistry and Biophysics III, 358-364.

Strunk, C. (1963). Über die Substruktur der Hyphenspitzen von Polystictus versicolor Zeitschrift für allgemeine Mikrobiologie 3, 265-274.

Strunk, C. (1968). Zur Darstellung des Apicalporus bei Polystictus versicolor. Archiv für Mikrobiologie 6o, $255-261$.

TraceY, M. V. (1955). In Moderne Methoden der Pflanzenanalyse, vol. 2, p. 272. Edited by M. V. Tracey \& K. Paech. Berlin: Springer-Verlag.

Wessels, J. G. H. (1965). Morphogenesis and biochemical processes in Schizophyllum commune. Wentia I3, I-I I3. 
WesSels, J. G. H. (1966). Control of cell-wall glucan degradation during development in Schizophyllum commune. Antonie van Leeuwenhoek 32, 34I-355.

Zevenhuizen, L. P. T. M. \& Bartnicki-GarCia, S. (I969). Chemical structure of the insoluble hyphal wall glucan of Phytophthora cinnamomi. Biochemistry 8, 1496-1502.

\section{EXPLANATION OF PLATES}

All electron micrographs, except where otherwise stated, are reproduced at a standard magnification of $\times 15,000$. Shadow-cast preparations were shadowed $\mathrm{Au} / \mathrm{Pd}$. Material was fixed either in glutaraldehyde $/ \mathrm{OsO}_{4}$ or $\mathrm{KMnO}_{4}$.

\section{Plate I}

Neurospora crassa, 5 day culture.

Fig. I and 2. Apex and sub-apical region of hypha, respectively, in buffer solution. Note variably granular appearance.

Fig. 3 and 4 . Same regions after $48 \mathrm{~h}$. treatment with chitinase. Note little difference from appearance in buffer alone.

Fig. 5 and 6. Same regions after 48 h. treatment with Pronase. Note virtually no alteration from appearance in buffer alone.

Plate 2

Neurospora crassa, 5 day culture.

Fig. 7. Appearance of apex of hypha after $48 \mathrm{~h}$. treatment with laminarinase. Note cratered appearance and extension of coarse strands of (?) glycoprotein almost to apex.

Fig. 8 and 9. Appearance of sub-apical regions of hypha after 48 h. treatment with laminarinase. Note in fig. 8 the predominantly longitudinally running strands which are orientated parallel to the long axis of the hypha, and some cratering.

Fig. Io. Appearance of sub-apical region of hypha after $5 \mathrm{~min}$. treatment with an ultrasonic disintegrator. Note coarse stranded appearance, the cratered region overlying a finely granular amorphous layer (AL) and being itself overlain in places with apparently structureless material (SM).

Fig. I I. Appearance of sub-apical region of hypha after successive laminarinase/Pronase treatments. Note the appearance of a coarsely stranded reticulum which can be seen to the left of the arrow, at the periphery of the hypha, outside an inner amorphous layer.

Fig. I2. Treatment and region as in fig. 10. Here the reticulum of coarsely stranded (?) glycoprotein has become detached from, and slipped off the underlying granular amorphous region which can be seen to the right (arrowed).

\section{Plate 3}

Neurospora crassa, 5 day culture.

Fig. 13. Tangential section through reticulum region of hyphal wall after successive laminarinase/ Pronase treatment. The network structure of the reticulum is clearly visible $\left(\mathrm{KMnO}_{4}\right.$ fixation), $\times 20,000$.

Fig. I4 to 17. Further consequences of laminarinase/Pronase treatment. The reticulum is losing its stranded form and breaking down under enzyme action (fig. 14) revealing a granular amorphous layer beneath (fig. 15). Continued Pronase treatment results in the gradual dissolution of this granular layer to reveal randomly arranged chitin microfibrils at the apex (fig. 16) and in sub-apical regions (fig. 17).

Fig. I8. Consequence of successive laminarinase/Pronase/chitinase treatment. The residual microfibrillar elements are totally disorganized.

\section{Plate 4}

Schizophyllum commune, 5 day culture.

Fig. I9 and 20. Apex and sub-apical region of a hypha, respectively, in buffer solution. Note finely and evenly granular appearance with little or no pitting.

Fig. $2 \mathrm{I}$ and 22. Same regions after treatment for $17 \mathrm{~h}$. with cold $\mathrm{KOH}$. Note the granular appearance still persists but the surface has been eroded irregularly by the treatment.

Fig. 23 and 24. Same regions after successive $\mathrm{KOH} /$ laminarinase treatments. Note that microfibrils are becoming apparent beneath the amorphous, finely granular matrix. 

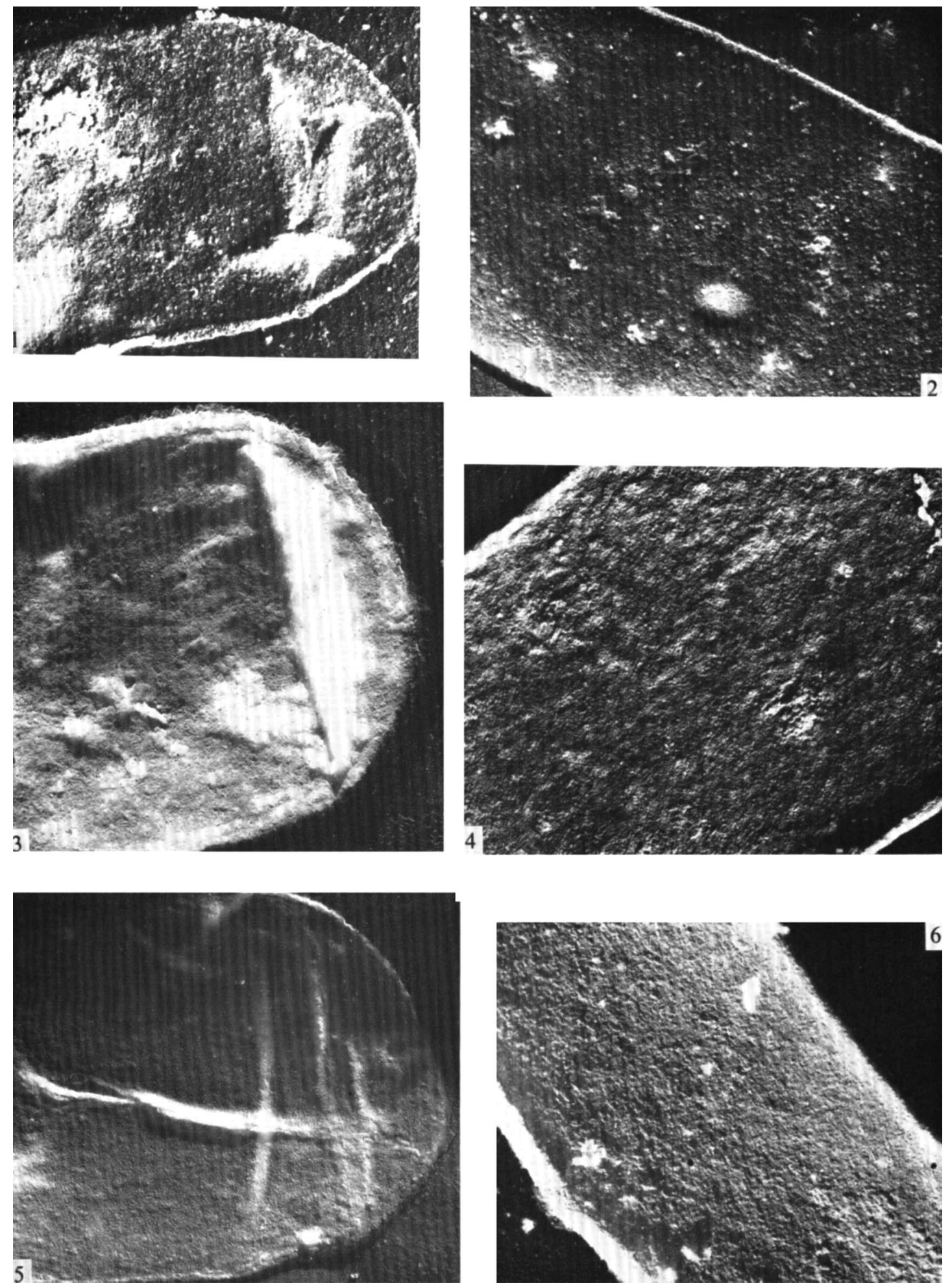

D. HUNSLEY AND J. H. BURNETT

(Facing p. 216) 

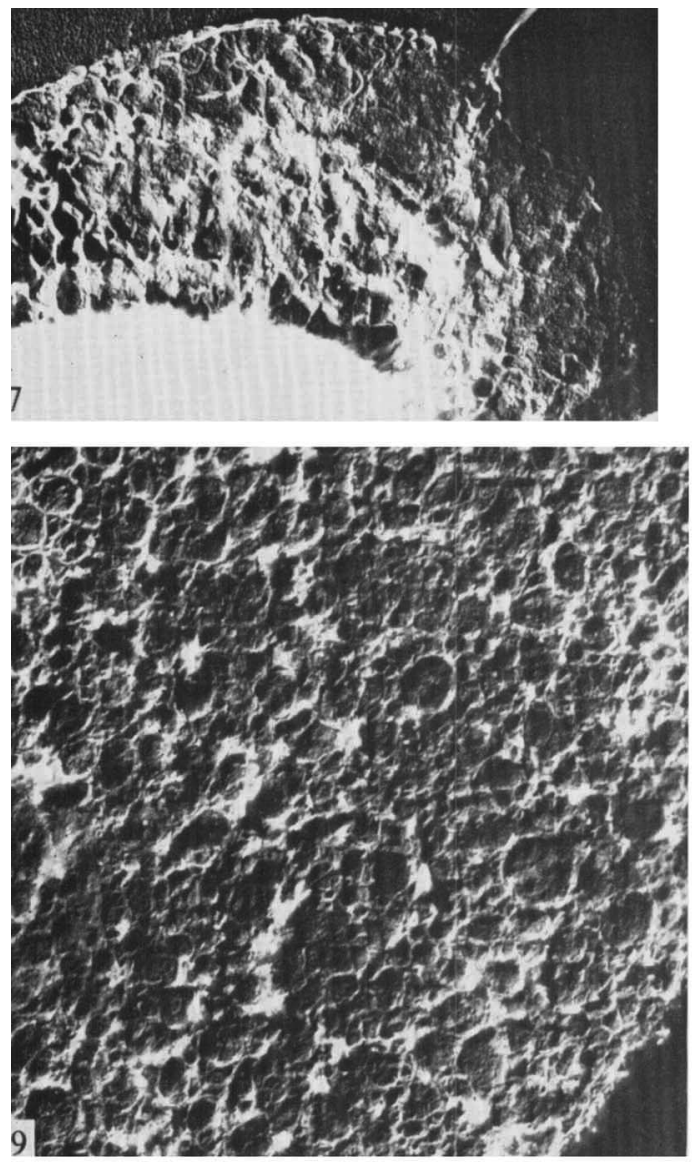
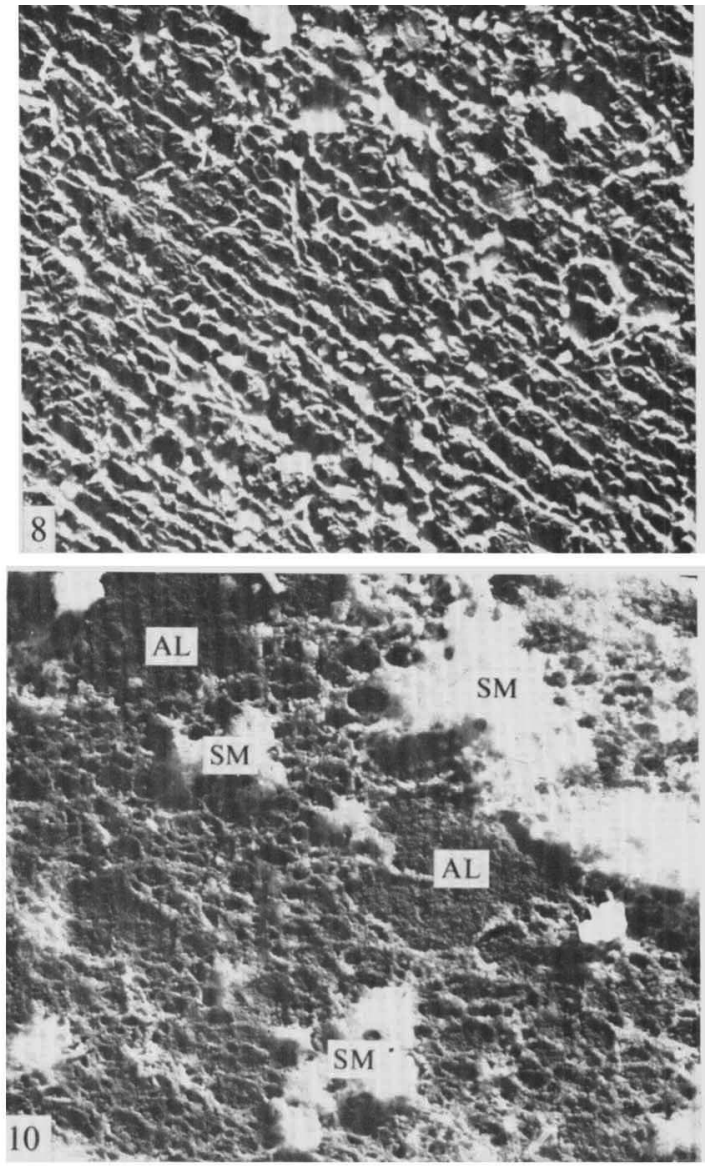
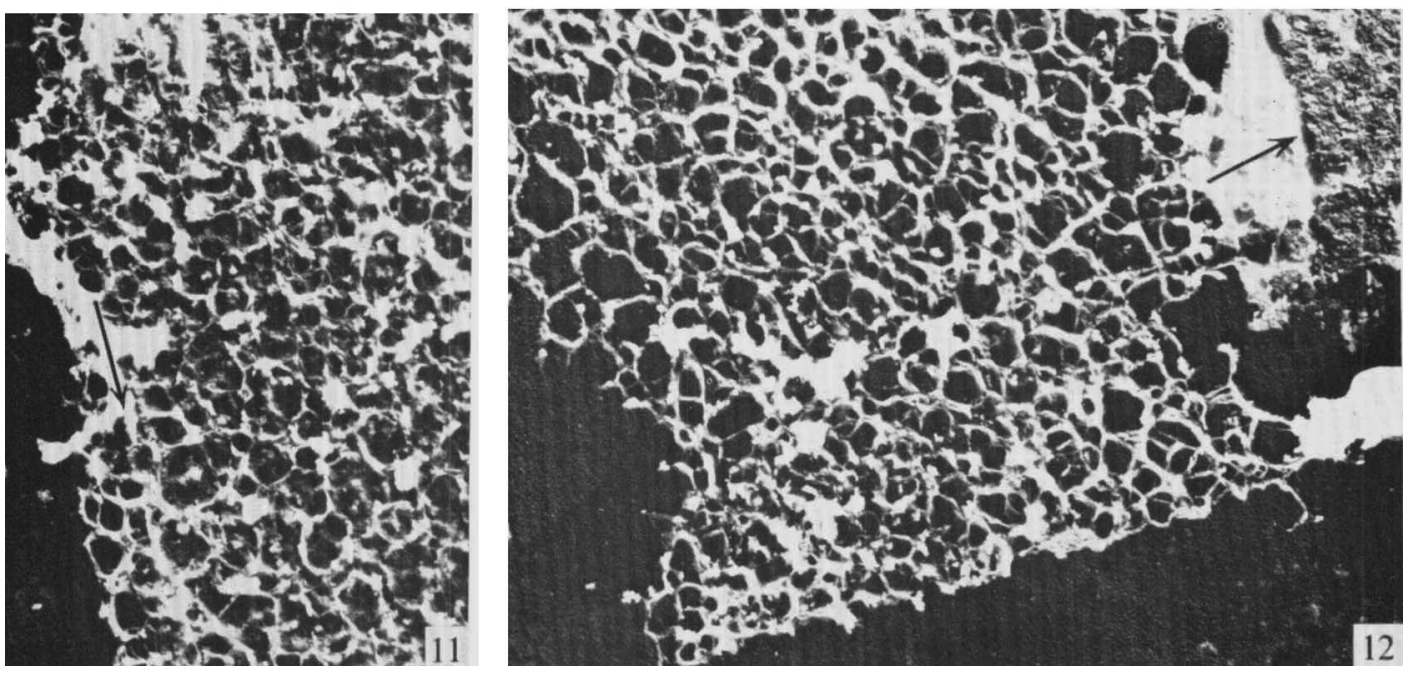

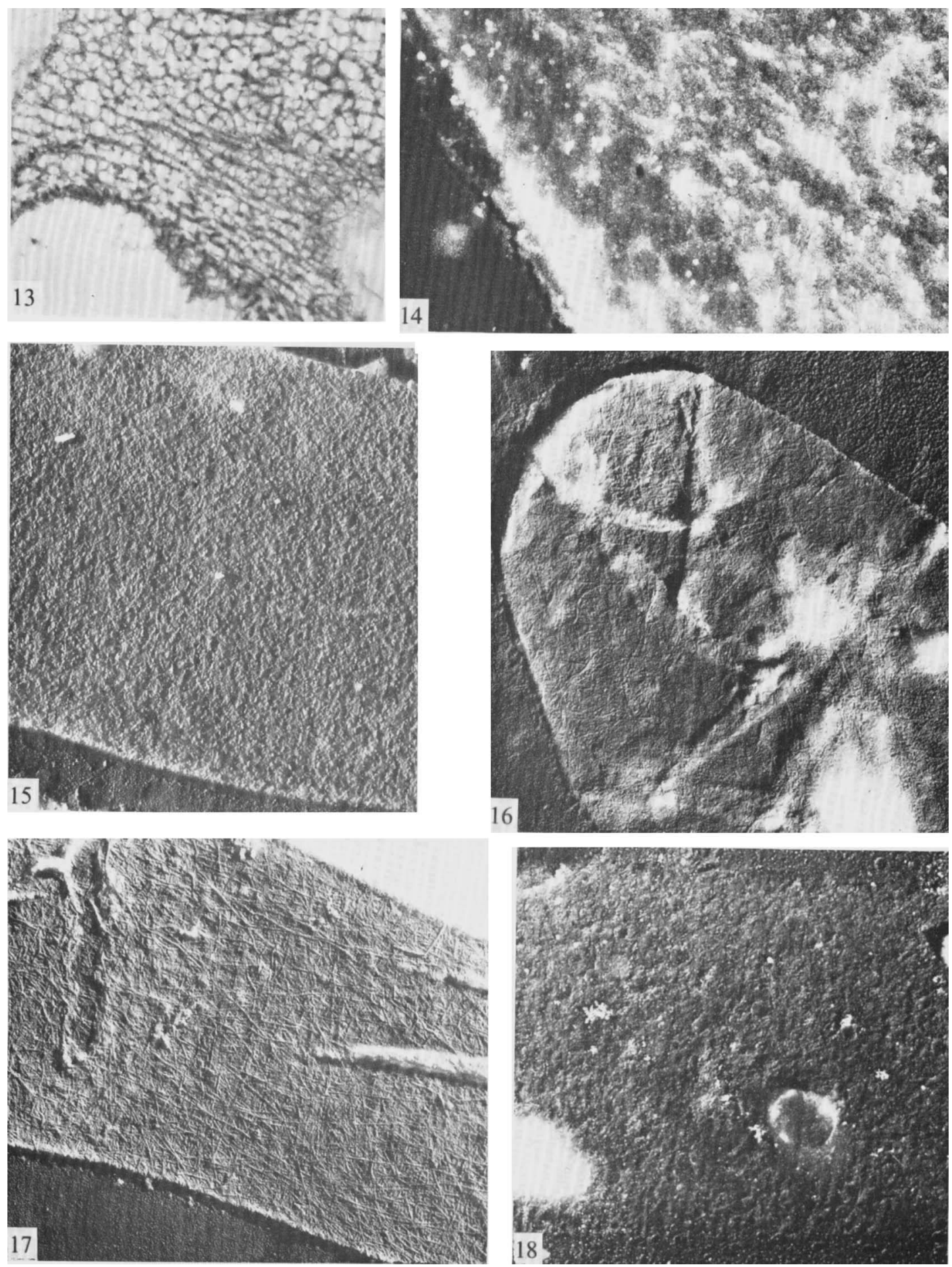

D. HUNSLEY AND J. H. BURNETT 

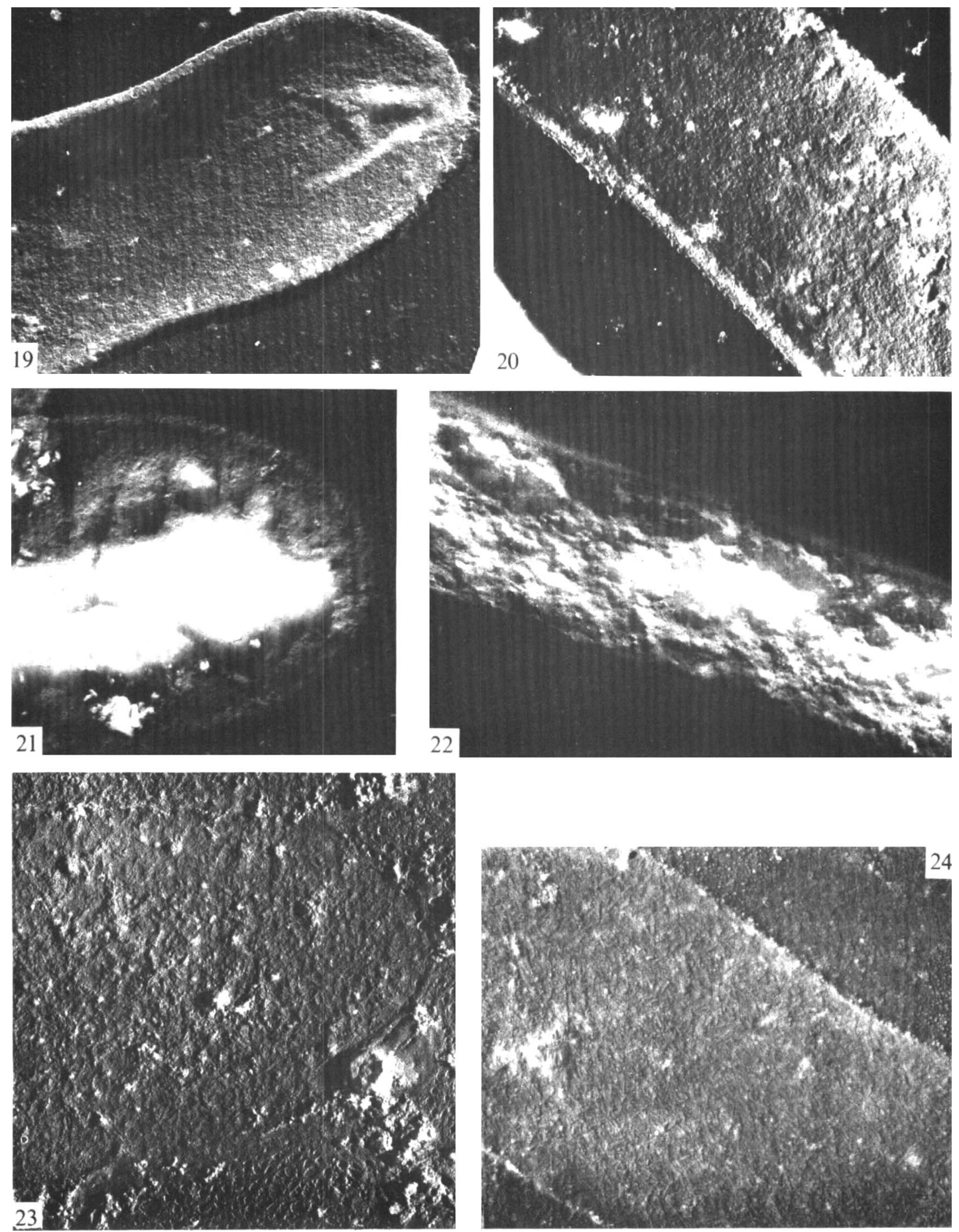

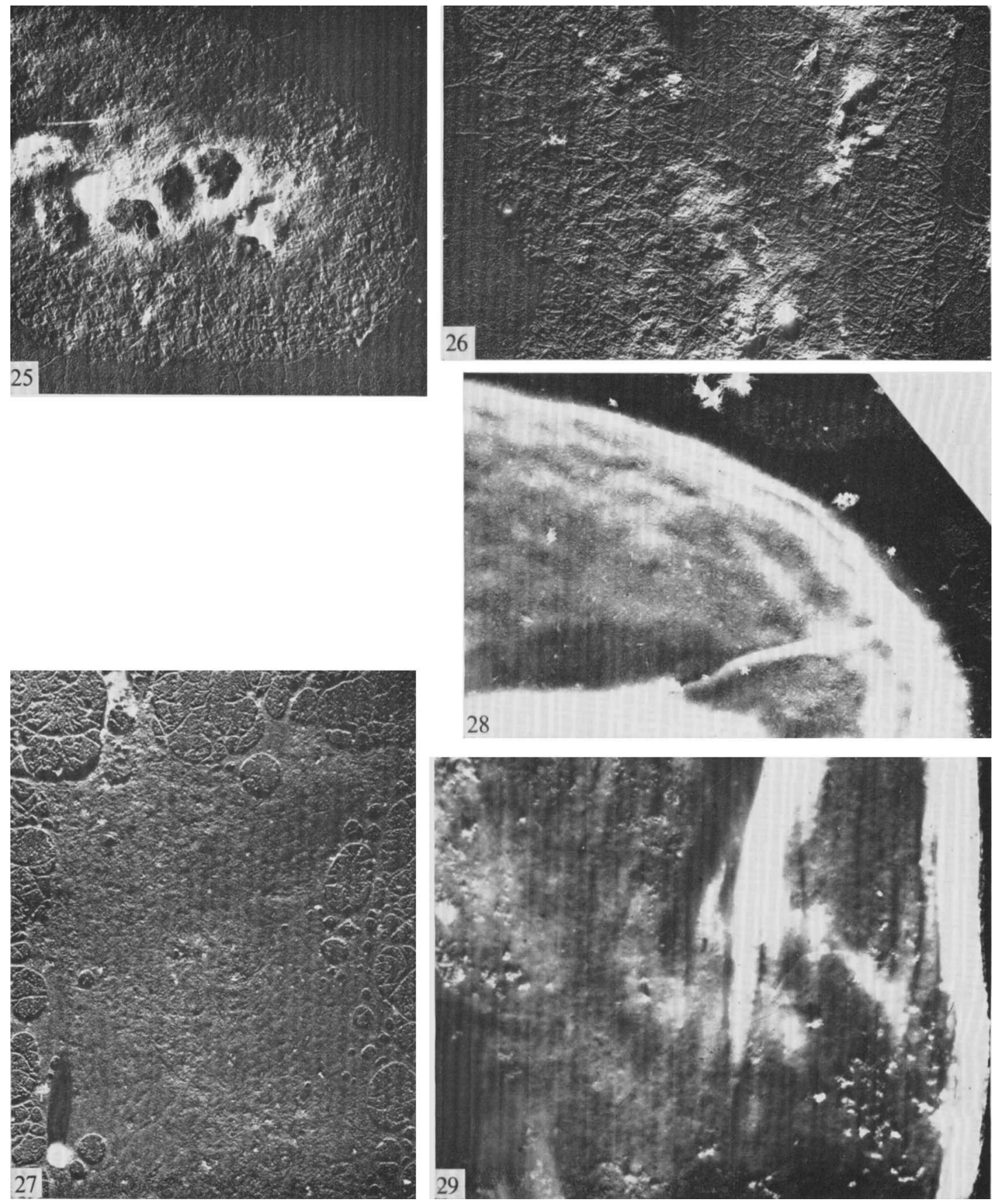

D. HUNSLEY AND J. H. BURNETT 

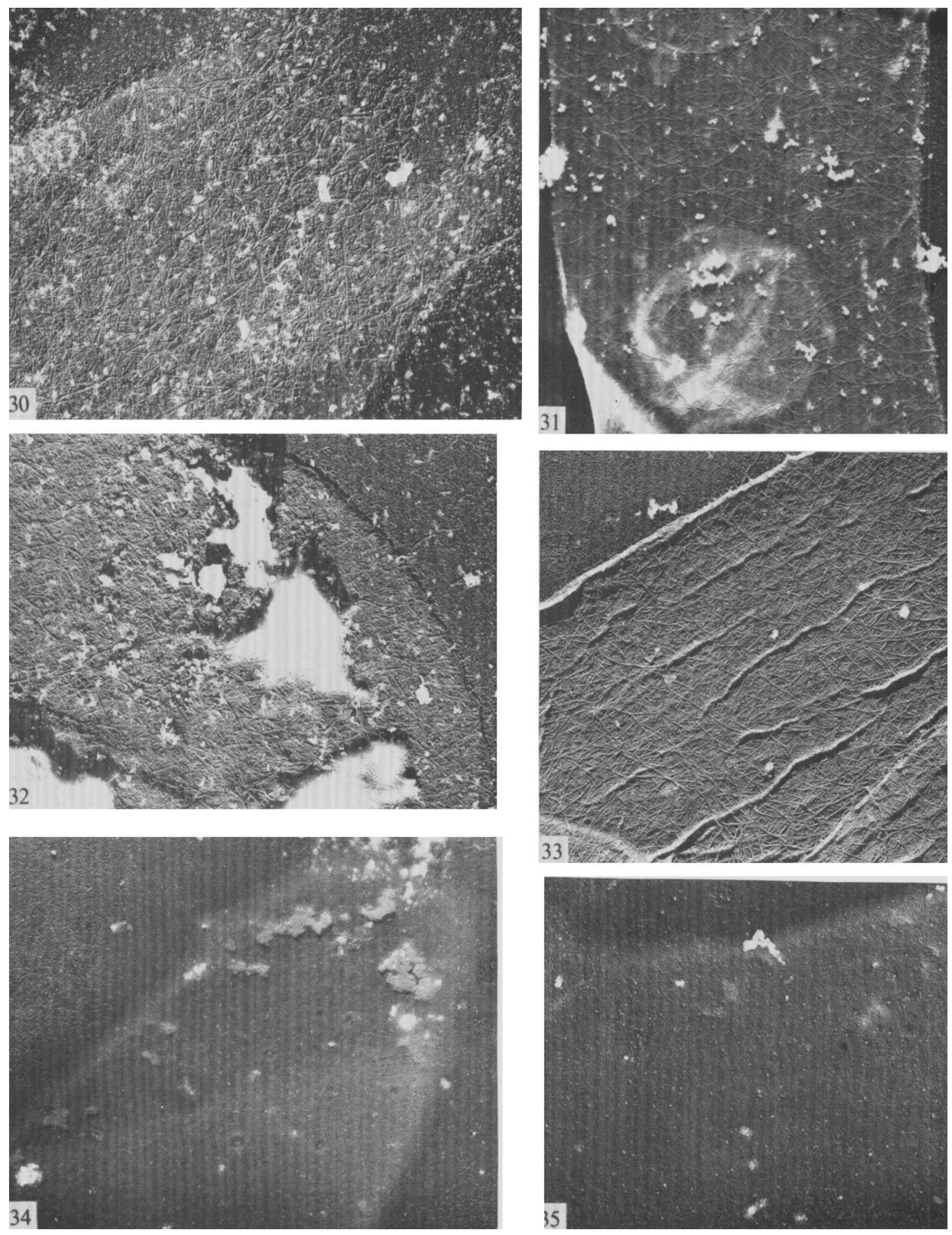

D. HUNSLEY AND J. H. BURNETT 


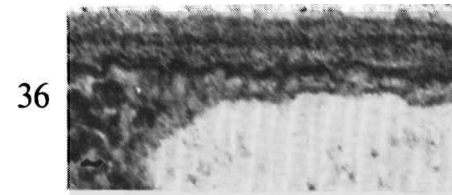

37

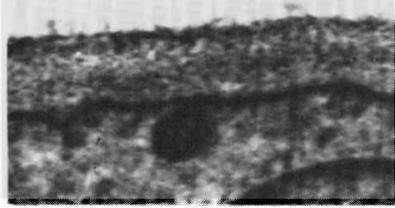

38
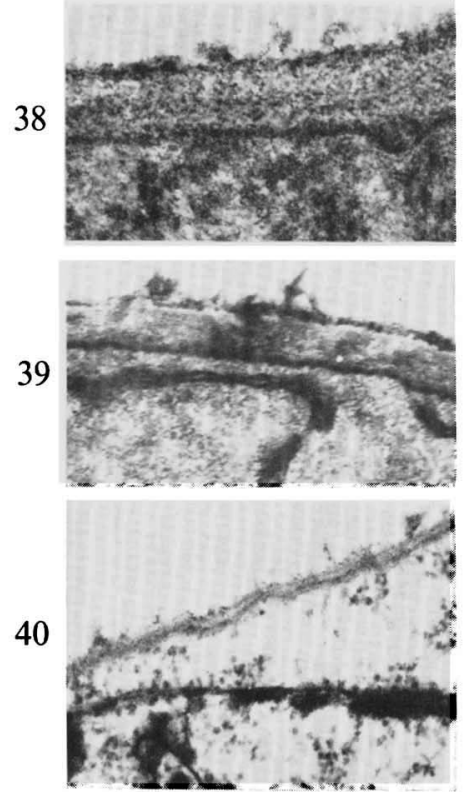

41

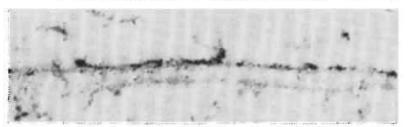

42

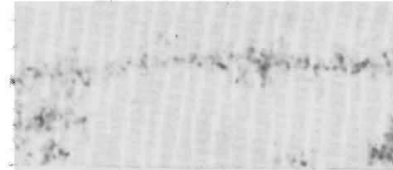

43

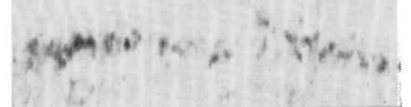

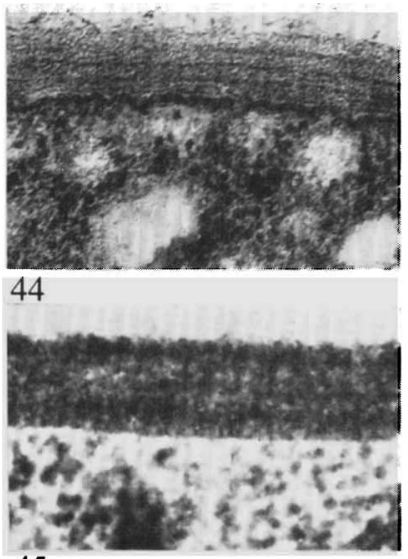

45

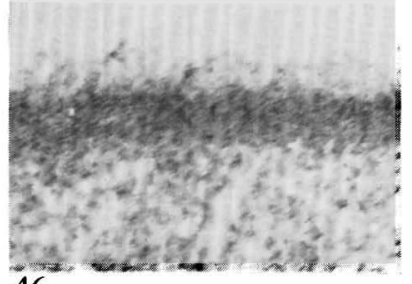

46

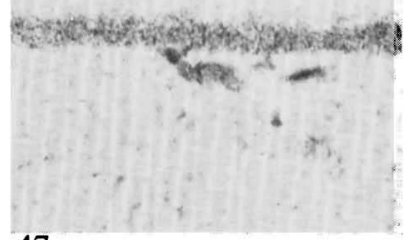

47

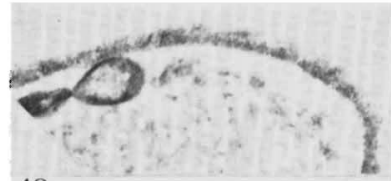

48

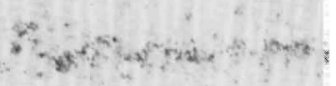

49
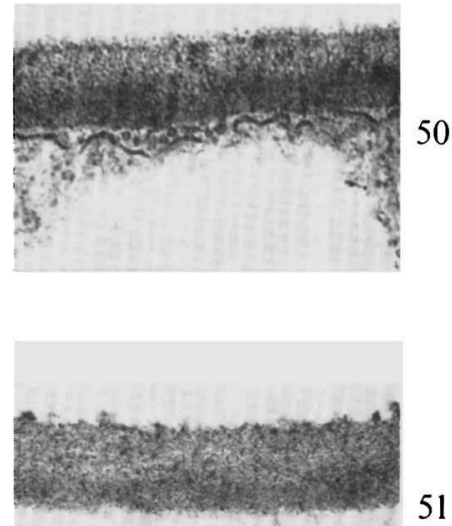

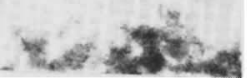
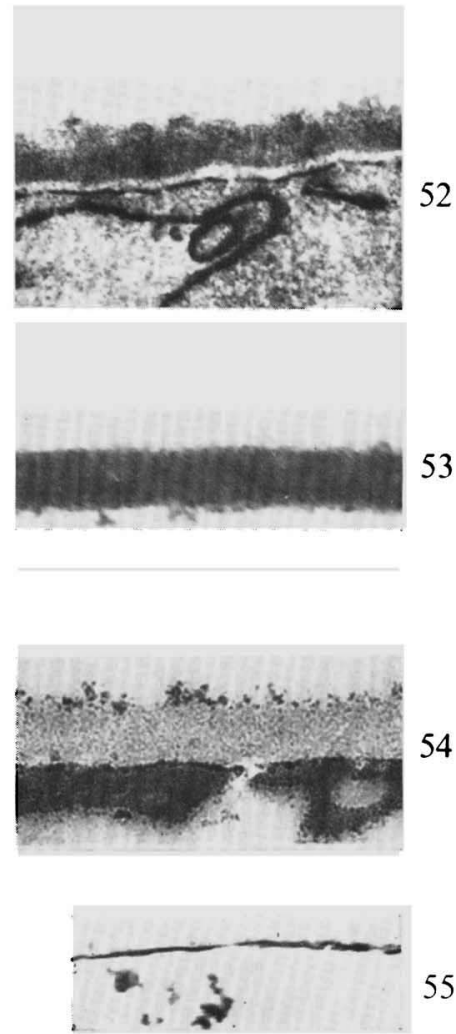

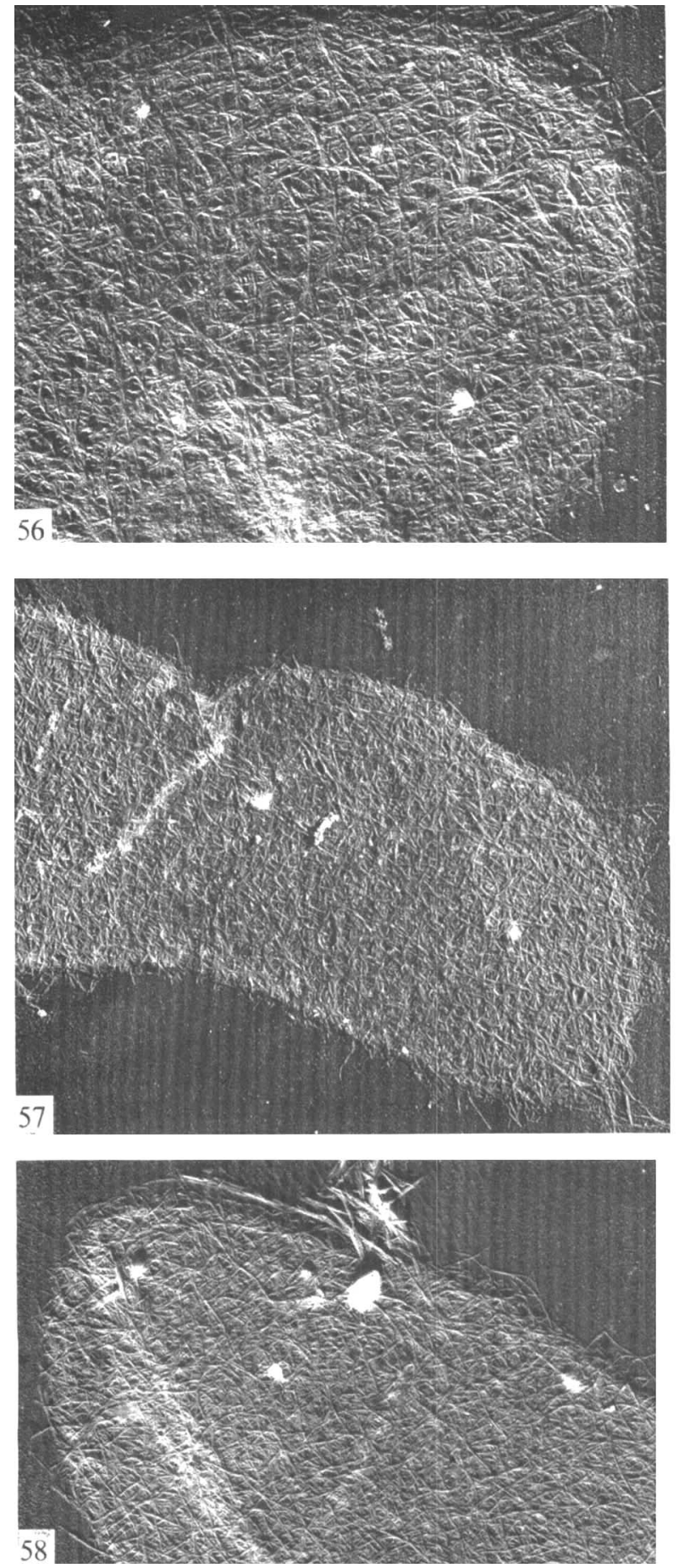
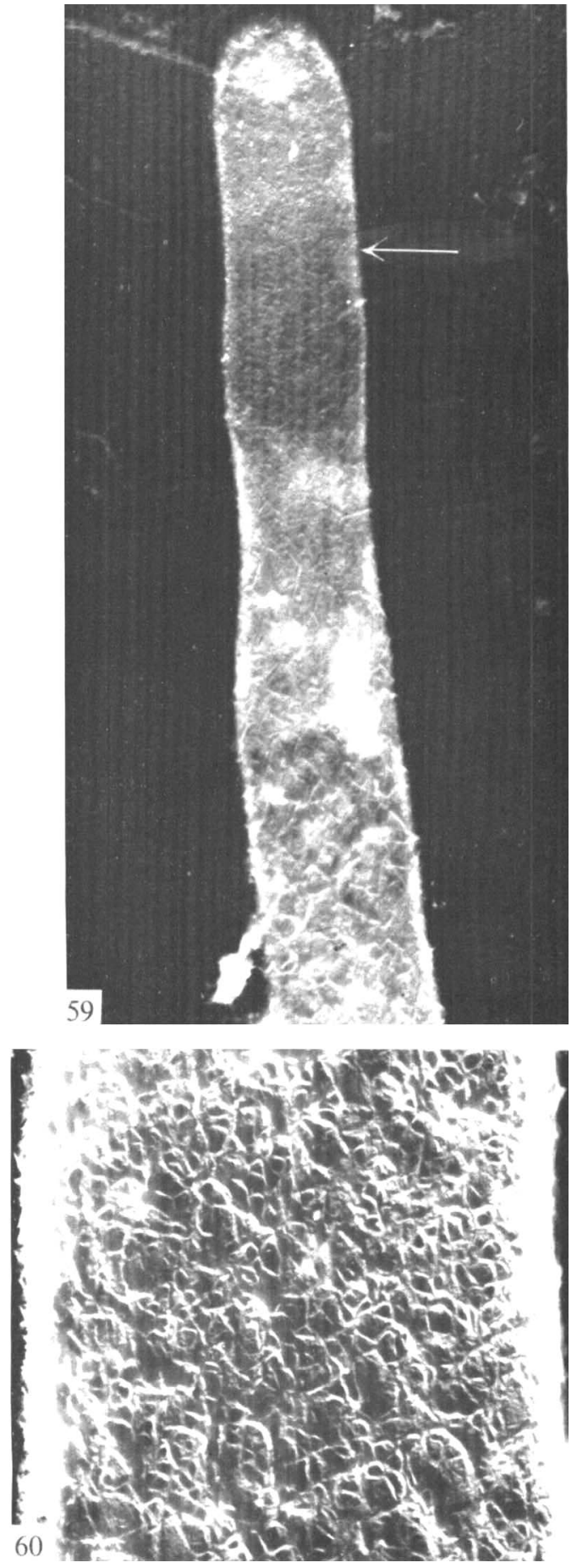


\section{Plate 5}

Schizophyllum commune, 5 day culture.

Fig. 25 and 26. Apex and sub-apical region of a hypha, respectively, after successive $\mathrm{KOH} /$ laminarinase/Pronase treatment. Note how the additional Pronase treatment has rendered the microfibrils more conspicuous, presumably by digesting encasing proteinaceous material around them. The microfibrils appear to be arranged at random.

Fig. 27. The consequence of successive $\mathrm{KOH} /$ laminarinase/Pronase/chitinase treatment. The structural identity of the chitin microfibrils has been lost.

Phytophthora parasitica, 5 day culture.

Fig. 28 and 29. Apex and sub-apical region of hypha, respectively, after incubation in buffer solution. Note the extremely finely granular, almost smooth appearance.

\section{Plate 6}

Phytophthora parasitica, 5 day culture.

Fig. 30 and 3I. Apex and sub-apical region of hypha, respectively, after $48 \mathrm{~h}$. laminarinase treatment. Note that microfibrils have become apparent in both regions. The apex has burst open at the tip and there is no evidence for an orderly arrangement of its microfibrils. There is, however, a suggestion of a predominantly transverse arrangement of microfibrils in, or on, an amorphous matrix in the sub-apical region.

Fig. 32 and 33. Same regions after successive laminarinase/Pronase treatments. Note that the microfibrils are now apparently more numerous and distinct. The suggestion of a predominantly transverse orientation in the sub-apical region has now been lost. (The elongated rippled structures in fig. 33 are artefactual folds in the wall material.)

Fig. 34 and 35. Same regions after successive laminarinase/cellulase treatment. Only 'ghost' images remain with no obvious evidence for any structural differentiation, but the form of apex and cylindrical hypha has persisted.

\section{Plate 7}

Transverse sections through the walls of hyphae of 5 day cultures of Neurospora crassa (fig. 36 to 43), Schizophyllum commune (fig. 44 to 49 ) and Phytophthora parasitica (fig. 50 to 55) after various treatments. (Fig. 36, 44, 50 glutaraldehyde/O $\mathrm{SO}_{4}$ fixation, remainder $\mathrm{KMnO}_{4}$ fixation.) All figures, $\times 40,000$.

\section{Neurospora crassa}

Fig. 36. Section through untreated wall taken direct from culture. Note the three-layered appearance with a central, more electron-dense region (cf. Text-fig. I B).

Fig. 37 to 39 . Sections through walls after buffer alone, laminarinase treatment and Pronase treatment, respectively. Note some loss of distinctness of central region but layered appearance still recognizable and unchanged in thickness.

Fig. 40. Section through laminarinase-treated wall. Note greatly reduced thickness comparable to that of innermost region of untreated wall.

Fig. 4I. Section through successive laminarinase/Pronase-treated wall. Note greater separation of regions compared with laminarinase-treated wall (fig. 40) and much greater electron transparency.

Fig. 42 and 43. Sections through successive laminarinase/chitinase and laminarinase/Pronase/ chitinase-treated walls, respectively. Note loss of electron density and, with the latter treatment, loss of structural identity. The laminarinase/chitinase-treated wall is thinner than a laminarinase-treated wall (fig. 40).

\section{Schizophyllum commune}

Fig. 44. Section through untreated wall taken direct from culture. Note four-layered appearance of comparable electron-dense regions separated by thin, more heavily electron-dense layers (cf. Textfig. 2 B).

Fig. 45. Section through wall after incubation in buffer showing some loss of distinctness of layered appearance but still recognizably four-layered. 
Fig. 46. Section through $\mathrm{KOH}$-treated wall. Note reduced thickness and loss of electron density, especially in peripheral region.

Fig. 47. Section through successive $\mathrm{KOH} /$ laminarinase-treated wall. Note further reduction in thickness and development of scattered electron-transparent regions.

Fig. 48. Section through successive $\mathrm{KOH} /$ laminarinase/Pronase-treated wall; the reduction in wall thickness is even greater.

Fig. 49. Section through successive $\mathrm{KOH} /$ laminarinase/Pronase/chitinase-treated wall: all structural integrity has now been lost.

\section{Phytophthora parasitica}

Fig. 50 and $5 \mathrm{I}$. Section through untreated wall taken direct from culture and from buffer, respectively. There is an outer, less electron-dense, and an inner, more electron-opaque layer (cf. Text-fig. 3 B). The appearance in buffer is comparable.

Fig. 52. Section through laminarinase-treated wall. Note uneven dissolution of outer region and consequent reduction in thickness.

Fig. 53. Section through successive laminarinase/Pronase-treated wall. Somewhat thicker than a laminarinase-treated wall, it is less electron-dense and has unevenly distributed, partially electrontransparent regions.

Fig. 54. Section through successive laminarinase/cellulase-treated wall. Much thicker than either laminarinase- or laminarinase/Pronase-treated walls, its electron density is greatly reduced although there are evenly scattered, electron-opaque granules.

Fig. 55. Section through successive laminarinase/Pronase/cellulase-treated wall: all structural integrity apparently lost. Laminarinase/cellulase/Pronase-treated walls are similar in appearance. Note plasmalemma is still intact.

\section{Plate 8}

Fig. 56 to 58. Apices of hyphae from 5 day cultures of Neurospora crassa, Schizophyllum commune and Phytophthora parasitica, respectively, shadowed after drastic chemical treatment. Note the presence of residual microfibrils of characteristically different dimensions in each species, which cover the whole apical region and are interwoven in an apparently random manner.

Fig. 59. N. crassa, 24 h. culture, shadowed hypha, otherwise untreated. Note characteristic, variably granular appearance at apex (cf. Pl. I, fig. I) but reticulum-like arrangement of ridges developing increasingly from the sub-apical region backwards. The first recognizable ridged region is arrowed, $\times 9000$.

Fig. 60. N. crassa, 24 h. culture, shadowed but otherwise untreated hyphal wall some way behind the apex. Note the well developed and characteristic pattern of ridges, reminiscent in their arrangement of the reticulum region illustrated in enzyme-treated walls of 5 day cultures in Pl. 2, fig. II, I2; Pl. 3, fig. I3. This pattern is, indeed, believed to be due to the reticulum region showing through the very thin outermost glucan layer of a $24 \mathrm{~h}$. culture. 